\title{
PERANCANGAN SISTEM INFORMASI AKUNTANSI YANG BANKABLE
}

\author{
Rahmanita Vidyasari \\ Jurusan Akuntansi, Politeknik Negeri Jakarta \\ Jl. Prof. Dr. G. A. Siwabessy, Kampus UI, Depok 16425 \\ rahmanita.vidyasari@akuntansi.pnj.ac.id
}

\begin{abstract}
In an effort to encourage community empowerment, especially in small and medium enterprises (SMEs), comprehensive support from financial institutions is needed, namely by applying for a credit for capital. In submitting a credit application to a financial institution, good and correct financial records minimum financial statement of the income statement and a statement of financial position (balance sheet) are required. The purpose of this study is to design an accounting information system that can provide information about sales data, purchase data and bankable financial statements (fulfilling the requirements for credit submission) in Small and Medium Enterprises in the Alam Sehat Apotics. The research method used is a qualitative approach. Using purposive sampling, the data sources used are primary data and secondary data. Data collection techniques are observation, interviews, and study of related documents. The data analysis technique used in this research is qualitative descriptive analysis. The PIECES method was used in the analysis to determine financial system weaknesses at the Alam Sehat Apotics. The software used is Visual Basic 2010 and Microsoft Access as the database. Information system design is represented through Data Flow Diagram (DFD) diagrams and Entity Relationship Diagrams (ER Diagrams). The results of this study are accounting information systems that can help the Alam Sehat Apotics record all sales and purchase transactions and display reports that are bankable and in accordance with SAK EMKM
\end{abstract}

Keywords : Accounting Information Systems, financial statements, bankable

\begin{abstract}
ABSTRAK
Dalam upaya mendorong pemberdayaan masyarakat, khususnya usaha kecil, dan menengah (UKM) diperlukan dukungan yang komprehensif dari lembaga keuangan yaitu dengan permohonan kredit atas modal. Dalam pengajuan permohonan kredit ke lembaga keuangan dibutuhkan pencatatan keuangan yang baik dan benar yaitu diminta laporan keuangan minimal laporan laba rugi dan laporan posisi keuangan (neraca). Tujuan penelitian ini merancang sistem informasi akuntansi yang dapat memberikan informasi mengenai data penjualan, data pembelian serta laporan keuangan yang bankable (memenuhi persyaratan pengajuan kredit) pada Usaha Kecil dan Menengah Apotik Alam Sehat. Metode penelitian yang digunakan adalah pendekatan kualitatif. Teknik sampling menggunakan purposive sampling, sumber data yang digunakan adalah data primer dan data sekunder. Teknik pengumpulan data adalah observasi, wawancara, dan studi dokumen yang terkait. Teknik analisis data yang digunakan dalam penelitian ini adalah analisis deskriptif kualitatif. Analisis sistem menggunakan metode PIECES untuk mengetahui kelemahan sistem keuangan pada Apotik Alam Sehat. Software yang digunakan adalah Visual Basic 2010 dan Microsoft Access sebagai basis datanya. Perancangan sistem informasi direpresentasikan melalui diagram Data Flow Diagram (DFD) dan Entity Relationship Diagram (ER Diagram). Hasil dari penelitian ini adalah sistem informasi akuntansi yang dapat membantu Apotik Alam Sehat mencatat segala transaksi penjualan dan pembelian serta menampilkan laporan yang bankable dan sesuai dengan SAK EMKM.
\end{abstract}

Kata Kunci : Sistem Informasi Akuntansi, laporan keuangan, bankable

\section{PENDAHULUAN}

\section{Latar Belakang}

Persoalan yang dihadapi UMKM di kota

Depok terkendala pada masalah permodalan. Melalui Kementerian Koprasi dan Usaha Kecil dan Menengah RI membuat sebuah upaya untuk membantu permodalan UMKM yaitu dengan menerbitkan Kredit Usaha Rakyat (KUR) namun tidak berjalan lancar. Salah satu penyebabnya adalah adalah kurangnya informasi yang memadai berupa laporan keuangan yang dihasilkan oleh UMKM. Hal 
ini terjadi karena banyak UMKM lebih berfokus pada kegiatan operasional sehingga pencatatan praktik akuntansi dan pelaporan keuangan sering terabaikan.

Dalam pengajuan permohonan kredit ke lembaga keuangan/perbankan dibutuhkan pencatatan/pembukuan keuangan yang baik dan benar salah satunya adalah membuat laporan keuangan minimal laporan laba rugi dan neraca. Hal ini diperberat lagi dengan adanya Undang-undang perpajakan tentang pengenaan $\mathrm{PPh}$ final 1\% dari peredaran bruto bagi UMKM.

UMKM yang menjadi subjek penelitian ini adalah Apotik Alam Sehat merupakan salah satu Usaha Mikro Kecil Menengah di Kecamatan Pancoran Mas, Depok yang memenuhi karakteristik UMKM dalam Undang-Undang No. 20 Tahun 2008 tentang UMKM. Dalam melaksanakan praktik penjualan dan pembelian obat serta pelaporan keuangan Apotik Alam sederhana dan dilakukan secara konvensional, sehingga masih memiliki kemungkinan untuk menghasilkan informasi yang tidak valid dan berakibat dengan pengambilan keputusan yang tidak tepat yang mempengaruhi kepercayaan pelanggan dan supplier. Selain itu karyawan masih membutuhkan waktu yang cukup lama dalam menghitung dan membuat laporan keuangan. Untuk itu dalam penelitian ini menerapkan Sistem Informasi Akuntansi yang sesuai dengan keadaaan Apotik Alam Sehat

\section{Permasalahan}

1. Bagaimana mengatasi sistem pencatatan pembelian dan penjualan yang masih konvensional?

2. Bagaimana membuat sistem informasi yang mampu mengolah data penjualan dan pembelian sehingga dapat menghasilkan laporan keuangan yang bankable dan sesuai dengan SAK EMKM?

\section{Tujuan}

Tujuan dari penelitian ini adalah untuk merancang sebuah sistem informasi akuntansi sesuai kebutuhan Apotik Alam Sehat yang dapat mencatat segala transaksi perdagangan serta menyajikan laporan-laporan keuangan yang di butuhkan serta bankable.

Manfaat dari penelitian ini adalah untuk membantu Apotik Alam Sehat dalam pengolahan data pembelian dan penjualan, meningkatkan efektifitas kerja karyawan serta membantu pemilik Apotik Alam Sehat dalam menghasilkan laporan keuangan yang bankable sehingga nantinya dapat digunakan saat pengajuan kredit ke lembaga keuangan

\section{TINJAUAN PUSTAKA}

\section{Usaha Mikro Kecil Menengah}

Dalam UU No. 20 Tahun 2008, yang dimaksud usaha kecil adalah usaha ekonomi produktif berdiri sendiri, yang dilakukan oleh perorangan, atau badan usaha yang bukan merupakan anak perusahaan atau bukan cabang perusahaan yang dimiliki, dikuasai, atau menjadi bagian baik langsung maupun tidak langsung dari usaha menengah atau usaha besar yang memiliki kriteria usaha kecil sebagaimana yang dimaksud didalam UndangUndang, yaitu:

Tabel 1. Pembagian Kelompok Usaha UMKM

\begin{tabular}{|l|l|l|}
\hline \multirow{2}{*}{ Nama Usaha } & Kriteria \\
\cline { 2 - 3 } & Aset & Omzet \\
\hline Usaha Mikro & $\begin{array}{l}\text { Maks 50 } \\
\text { juta }\end{array}$ & Maks 300 juta \\
\hline Usaha Kecil & $\begin{array}{l}>50 \text { juta }- \\
500 \text { juta }\end{array}$ & $\begin{array}{l}>300 \text { juta }- \\
\text { 2.5 Miliar }\end{array}$ \\
\hline $\begin{array}{l}\text { Usaha } \\
\text { Menengah }\end{array}$ & $\begin{array}{l}>500 \text { juta - } \\
10 \text { miliar }\end{array}$ & $\begin{array}{l}>2.5 \text { miliar }- \\
50 \text { miliar }\end{array}$ \\
\hline
\end{tabular}

Sistem Informasi Akuntansi

(Romney \& Steinbart, 2014) berpendapat bahwa Sistem Informasi Akuntansi adalah suatu sistem yang mengumpulkan, mencatat, menyimpan, dan mengolah data untuk menghasilkan informasi bagi pengambil kep utusan. Terdapat enam komponen Sistem Informasi Akuntansi menurut (Romney \& Steinbart, 2014) yaitu:

a. Orang yang menggunakan sistem.

b. Prosedur dan instruksi yang digunakan untuk mengumpulkan, memproses, dan menyimpan data.

c. Data mengenai organisasi dan aktivitas bisnisnya.

d. Software yang digunakan untuk memproses data.

e. Infrastruktur teknologi informasi, termasuk komputer, peralatan pendukung (peripheral device), dan peralatan untuk komunikasi yang digunakan dalam SIA.

f. Pengendalian internal dan pengukuran keamanan yang menyimpan data SIA.

\section{Laporan Keuangan}

Menurut (Priyati, 2013) definisi laporan keuangan adalah hasil akhir dari suatu proses pencatatan, pengelolaan dan pemeriksaan dari 
transaksi finansial dalam suatu badan usaha yang dirancang untuk pembuatan keputusan baik dalam maupun luar perusahaan mengenai posisi keuangan dan hasil usaha perusahaan. Menurut SAK EMKM (2016), laporan keuangan entitas mikro, kecil dan menengah terdiri dari Laporan Posisi Keuangan, Laporan Laba Rugi dan Catatan Atas Laporan Keuangan.

\section{Alat Bantu Perancangan Sistem DFD (Data Flow Diagram)}

DFD adalah suatu model logika data atau proses yang dibuat untuk menggambarkan darimana asal data dan kemana tujuan data yang keluar dari sistem, dimana data disimpan, proses apa yang menghasilkan data tersebut dan interaksi antara data yang tersimpan dan proses yang dikenakan pada data tersebut (Kristanto, 2018).

\section{Kamus Data}

Kamus data adalah kumpulan elemenelemn atau symbol-simbol yang digunakan untuk membantu dalam penggambaran atau pengidentifikasian setiap field atau file di dalam sistem (Kristanto, 2018).

\section{Blok Chart}

Block chart berfungsi memodelkan masukan, keluaran, proses maupun transaksi dengan menggunakan simbol-simbol tertentu. Pembuatan blok chart memudahkan bagi pemkai dalam memahami alur dari sistem atau transaksi.

\section{ER (Entity Relationship) Diagram}

Teknik ER menyediakan konsep yang bermanfaat yang dapat mengubah deskripsi informal dari apa yang diinginkan user menjadi hal yang lebih detail, presisi, dan deskripsi detail tersebut dapat diimplementasikan ke dalam DBMS (Database Management System) (Kristanto, 2018).

\section{Penelitian Terdahulu}

Menurut (Prihantara, 2012) dalam jurnalnya yang berjudul "Design dan Implementasi Sistem Informasi Apotek Pada Apotek Mitra Agung Pacitan" dijelaskan bahwa sistem informasi yang dibuat menghasilkan pencatatan transaksi penjualan dan pembelian obat, stok barang, dan pembuatan laporan kepada pimpinan berupa laporan kasir, laporan stok dan laporan laba penjualan.
Menurut (Aini \& Rifani, 2016) dalam artikelnya yang berjudul "Pengembangan Desain Sistem Informasi Akuntansi Pada Usaha Kecil dan Menengah Kampung Roti Surabaya" dijelaskan bahwa sistem informasi yang dibuat adalah sistem akuntansi penerimaan dan pengeluaran kas yang dapat menghasilkan laporan keuangan.

Dalam penelitian ini, akan dibangun sistem informasi apotik yang dapat mencatat semua transaksi perdagangan apotik dan dikembangkan pula sistem pencatatan keuangan yang sesuai dengan pencatatan keuangan akuntansi sehingga dapat menghasilkan laporan keuangan yang bankable yang nantinya dapat digunakan saat pengajuan kredit ke lembaga keuangan.

\section{METODE PENELITIAN}

Metode penelitian yang digunakan adalah pendekatan kulatitatif dengan metode studi kasus. Melalui metode penelitian ini penulis dapat memahami secara lebih mendalam mengenai objek yang diteliti. Objek penelitian yang digunakan dalam penelitian ini adalah keadaan Sistem Akuntansi pada Apotik Alam Sehat. Teknik sampling yang digunakan adalah purposive sampling, dimana penulis menggunakan penilaiannya dalam memilih sampel yang sesuai dengan tujuan penelitian ini. Sampel yang dipilih penulis dalam penelitian ini adalah pemilik serta karyawan bagian akuntansi dan keuangan (kasir) Apotik Alam Sehat.

Sumber data yang digunakan dalam penelitian ini adalah data primer dan data sekunder. Data primer berupa hasil wawancara dengan pemilik dan karyawan Apotik Alam Sehat serta hasil observasi langsung pada Apotik Alam Sehat serta data sekunder yang digunakan adalah catatan dan dokumendokumen yang berkaitan dengan aktivitas pencatatan keuangan yaitu transakasi penjualan tunai dan kredit, pembelian tunai dan kredit, serta pelaporan keuangan. Teknik pengumpulan data adalah observasi, wawancara, dan studi dokumen yang terkait. Teknik analisis data yang digunakan dalam penelitian ini adalah analisis deskriptif kualitatif. Data yang diperoleh akan dianalisis yang kemudian dilakukan perancangan sistem informasi akuntansi yang dimulai dari desain sistem yang meliputi desain proses, desain data, dan tampilan antar muka. 


\section{HASIL DAN PEMBAHASAN}

\section{Analisis Sistem}

Metode yang digunakan dalam menganalisis sistem adalah metode analisis PIECES (performance, information, economic, control, efficiency, and service) dengan tujuan untuk melihat analisis kelemahan sistem akuntansi yang digunakan sekarang dan membagi analisis kebutuhan sistem dengan analisis kebutuhan fungsional dan kebutuhan non-fungsional.

Hasil analisis PIECES didapatkan bahwa performance (kinerja) dari sistem pencatatan konvensional mengandalkan ketelitian manusia dan membutuhkan banyak waktu dan tenaga, dari sisi information (informasi) yang diperoleh kadang tidak akurat, bias dan tidak tepat waktu sehingga terlambat dalam pengambilan keputusan, dari sisi economic (ekonomi) masih banyak menggunakan buku dan kertas dalam pencatatan transaksi konvensional, dari sisi control (kontrol) riskan terhadap ketidaktelitian yang menyebabkan salah saji data pembelian, dari sisi efficiency (efisiensi) pencatatan dan pengolahan data untuk menghasilkan sebuah laporan membutuhkan banyak waktu dan tenaga pada aktivitas sumber daya manusia, dari sisi service (pelayanan) proses pembukuan yang lama berpeluang menghasilkan informasi yang bias, serta dapat terjadi adanya salah pencatatan angka dalam jumlah pembelian di pihak customer maupun jumlah pemesanan di pihak supplier.

\section{Kerangka Pemikiran}

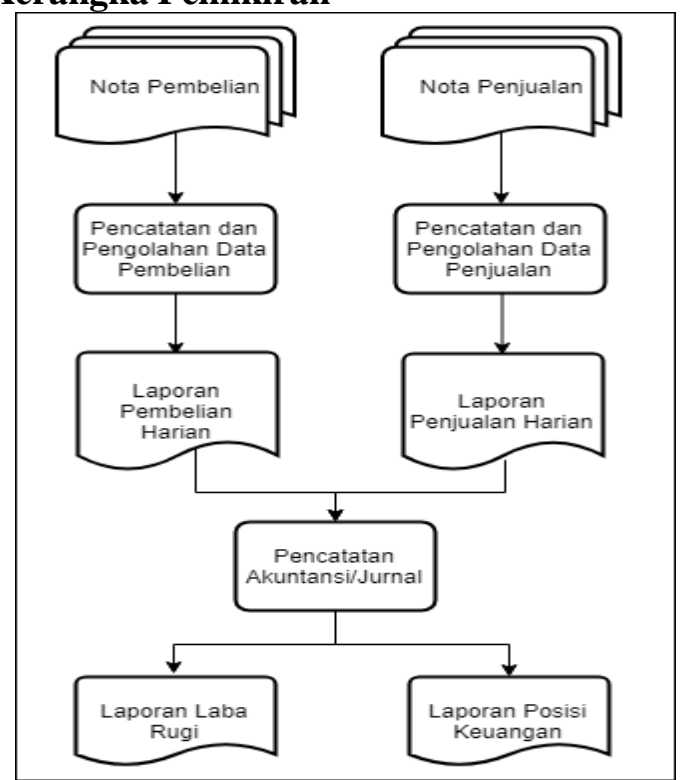

Gambar 1. Blok chart dari Sistem Informasi Akuntansi

\section{Perancangan Sistem}

Tahap perancangan sistem merupakan tahap menerjemahkan kebutuhan sistem yang telah didapat dari hasil kegiatan Analisis Sitem. Penelitian ini menggunakan Diagram Konteks dan DFD (Data Flow Diagram) untuk melihat aliran arus data.

\section{Perancangan DFD}

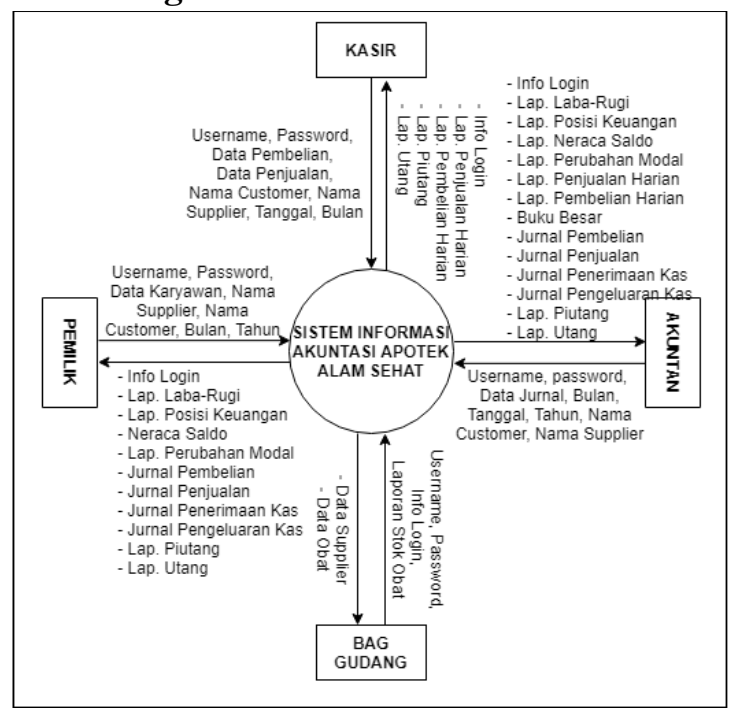

Gambar 2. Diagram Konteks Sistem

Pada Diagram Konteks terlihat ada empat pengguna yang menggunakan sistem ini, yaitu pemilik, kasir, akuntan dan bagiang gudang. Semua pengguna harus melakukan login terlebih dahulu untuk masuk ke dalam sistem, selanjutnya masing-masing pengguna memiliki menu-menu tersendiri.

Pemilik hanya mengelola data karyawan, selanjutnya hanya menerima laporan dari sistem diantaranya laporan utang dan piutang, laporan laba rugi, laporan posisi keuangan, dan neraca saldo. Kasir melakukan kegiatan yang berkaitan dengan uang yaitu pembayaran ataupun penjualan serta memasukkan data customer, selanjutnya kasir juga dapat melihat laporan penjualan dan pembelian harian, serta laporan utang dan piutang. Bagian gudang mengelola data supplier dan data obat, serta dapat melihat laporan persediaan stok obat. Akuntan atau bagian keuangan mengelola data jurnal, agar dapat menghasilkan laporan-laporan keuangan yang berkaitan dengan akuntansi. 


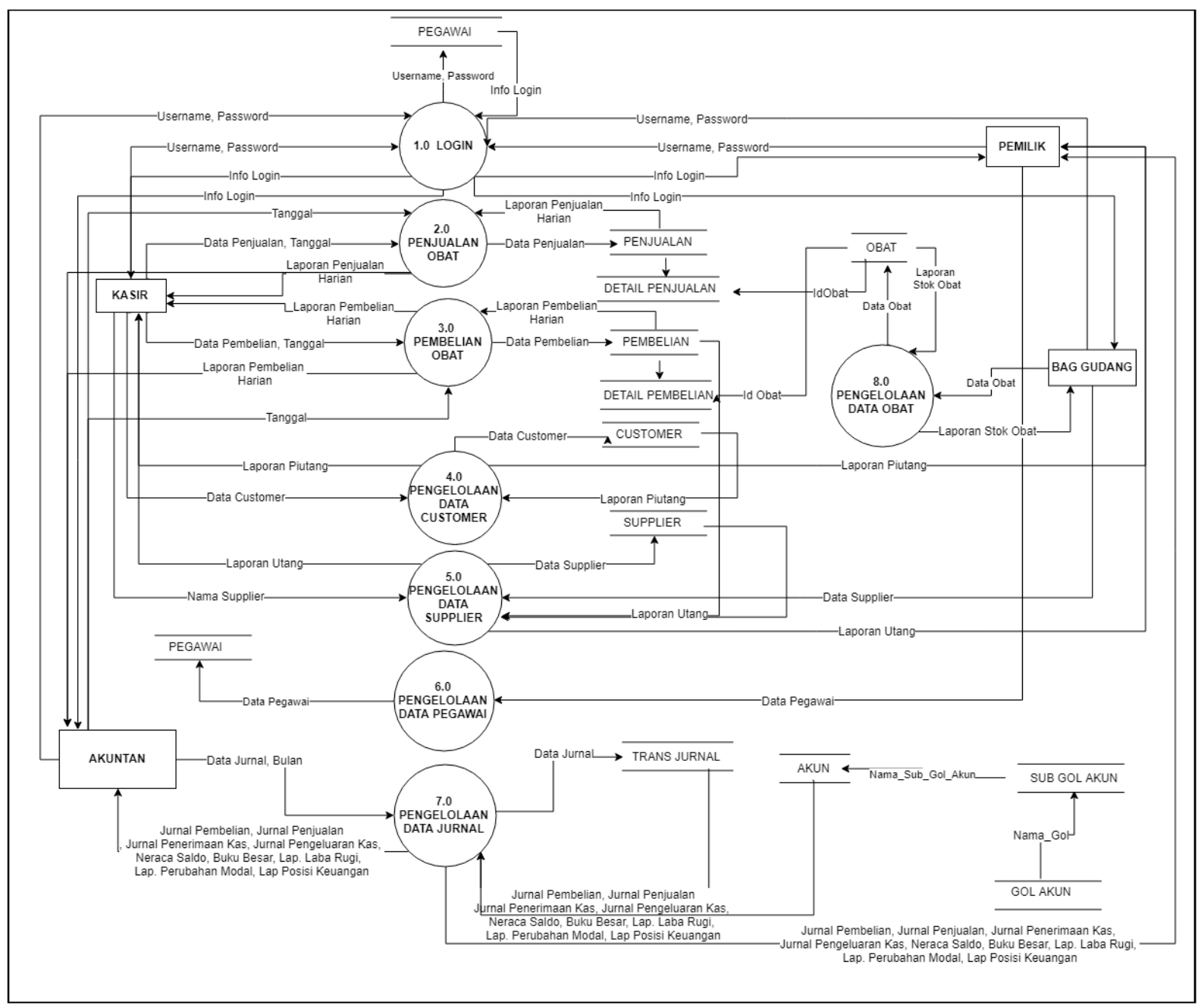

Gambar 3. DFD level1

Pada DFD Level 1 terdapat 7 proses, dan beberapa proses terdapat subproses yang digambarkan dengan DFD Level 2.

\section{Perancangan Basis Data}

Pemodelan konseptual basis data data menggunakan ER (Entity Relationship) Diagram yang merupakan pemodelan data konseptual dalam proses pengembangan basis data relasional (Nugroho, 2011). 


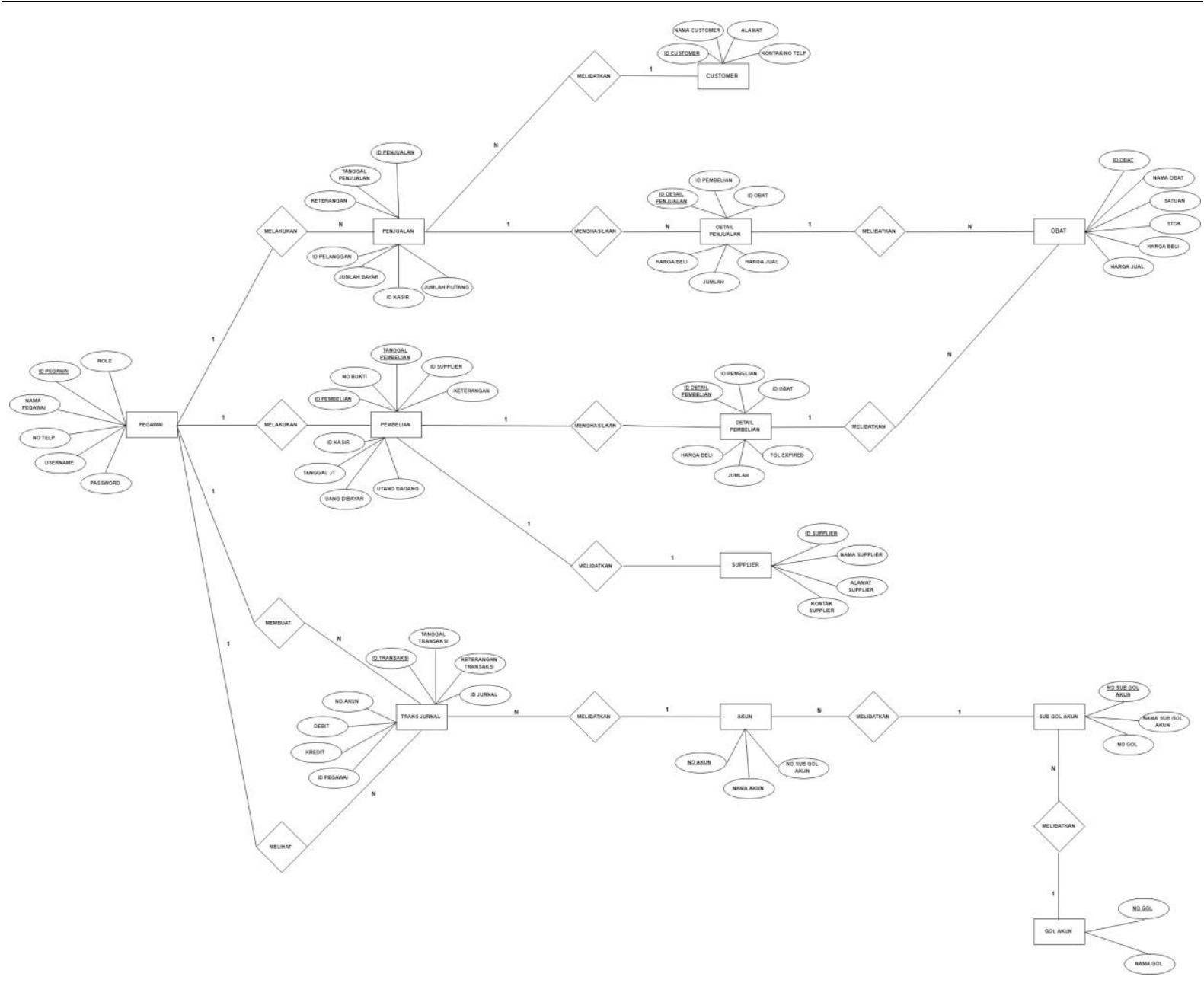

\section{Implementasi Sistem}

Gambar 4. ER Diagram

Hasil dari perancangan sistem diimplementasikan dengan code bahasa vb.net menggunakan tools Visual Basic 2010 dan menggunakan Microsoft Access 2016 sebagai databasenya. Diawali dengan login ke dalam sistem untuk memisahkan role untuk setiap pengguna. Selanjutnya untuk setiap pengguna memiliki menu masing-masing yang berbeda.

\section{Tampilan Program}

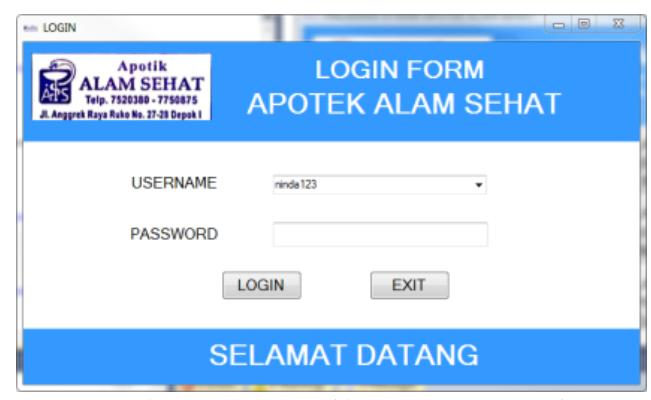

Gambar 5. Tampilan Menu Login

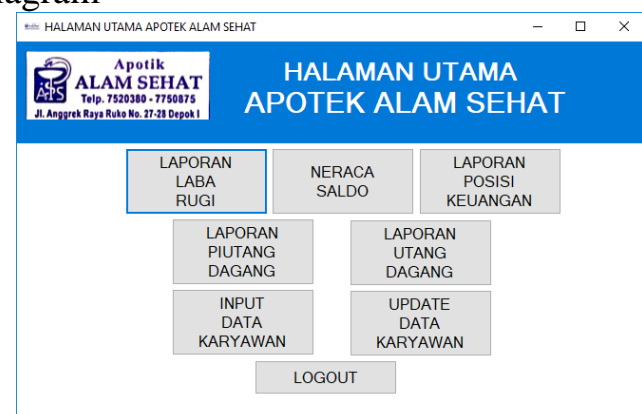

Gambar 6. Tampilan Menu untuk Pemilik

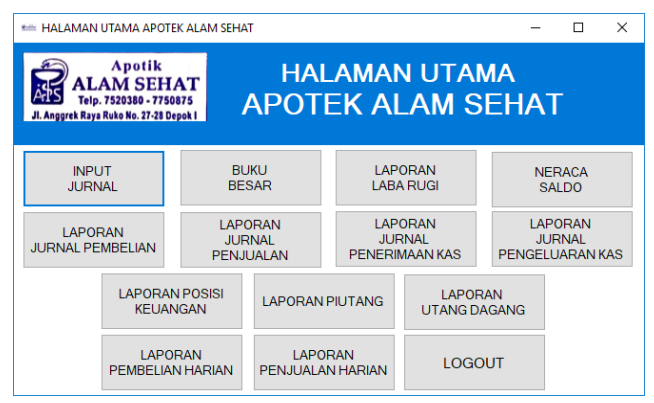

Gambar 7. Tampilan Menu untuk Akuntan 


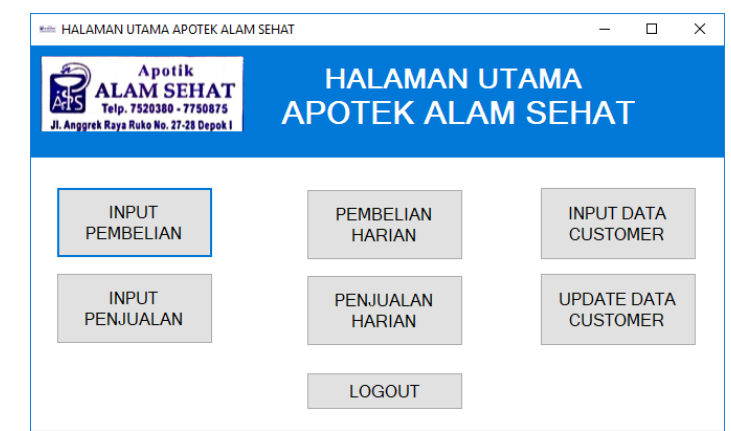

Gambar 8. Tampilan Menu untuk Kasir

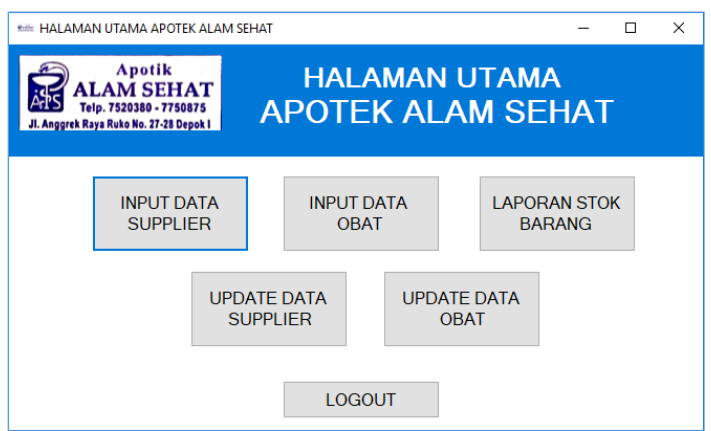

Gambar 9. Tampilan Menu untuk Bag. Gudang

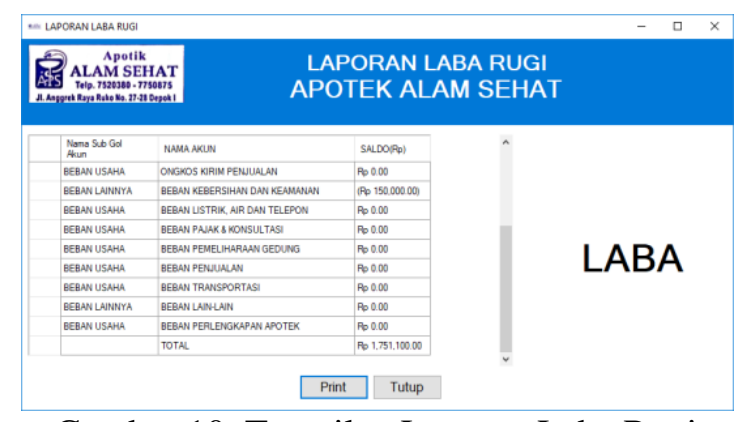

Gambar 10. Tampilan Laporan Laba Rugi

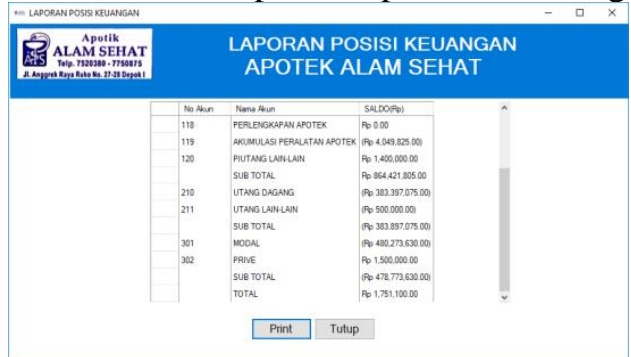

Gambar 11. Tampilan Laporan Posisi Keuangan

\section{SIMPULAN DAN SARAN}

\section{Simpulan}

1. Berdasarkan hasil analisis sistem terdapat terdapat banyak kelemahan dan permasalahan dari sistem terdahulu/konvensional seperti tidak efektivitasnya pengolahan dan pencarian data pembelian/penjualan ataupun pembuatan laporan keuangan.

2. Melalui perancangan sistem informasi akuntansi ini dapat membantu pencatatan segala transaksi perdagangan dari UKM Apotek Alam Sehat dan menghasilkan laporan keuangan yang bankable yaitu laporan laba rugi dan laporan posisi keuangan yang selanjutnya dapat digunakan untuk membantu pengambilan keputusan serta pengajuan kredit ke lembaga keuangan.

\section{Saran}

Pada aplikasi sistem informasi akuntansi Apotik Alam Sehat ini masih belum sempurna, diantaranya adalah sistem belum mencakup untuk pencatatan retur penjualan dan retur pembelian sehingga diharapkan ke depannya sistem dapat mencatat transaksi retur penjualan dan retur pembelian.

\section{DAFTAR PUSTAKA}

Aini, N., \& Rifani, L. (2016). Pengembangan Desain Sistem Informasi Akuntansi Pada Usaha Kecil dan Menengah Kampung Roti Surabaya. Seminar Nasional Sistem Informasi Indonesia. Surabaya: Departemen Sistem Informasi, Institut Teknologi Sepuluh Nopember.

Indonesia, I. A. (2016). Standar Akuntansi Keuangan Entitas Mikro, Kecil, dan Menengah. Jakarta.

Indonesia, R. (2008). Undang-Undang Nomor 20 tentang Usaha Mikro, Kecil dan Menegah. Jakarta.

Kristanto, A. (2018). Perancangan Sistem Informasi dan Aplikasinya. Yogyakarta: Gava Media.

Nugroho, A. (2011). Perancangan dan Implementasi Sistem Basis Data. Yogyakarta: Andi.

Prihantara, A. (2012). Design Dan Implementasi Sistem Informasi Apotek Pada Apotek Mitra Agung Pacitan. Journal Speed - Sentra Penelitian Engineering dan Edukasi, Vol 4 No 3: 1-7.

Priyati, N. (2013). Pengantar Akuntansi. Jakarta: PT. Indeks.

Romney, \& Steinbart. (2014). Accounting System (13th Ed). Jakarta: Salemba Empat. 